\title{
Acceptability of mentor mother peer support for women living with HIV in North-Central Nigeria: a qualitative study
}

\author{
Angela Odiachi ${ }^{1}$, Maryam Al-Mujtaba ${ }^{2,3}$, Nguavese Torbunde ${ }^{4,5}$, Salome Erekaha ${ }^{2,6}$, Abayomi J. Afe , \\ Ebun Adejuyigbe ${ }^{8}$, Hadiza S. Galadanci ${ }^{9}$, Tongdiyen L. Jasper ${ }^{2,10}$, Llewellyn J. Cornelius ${ }^{11 \dagger}$ and \\ Nadia A. Sam-Agudu $2,4,12^{*}+$
}

\begin{abstract}
Background: Mentor mothers provide psychosocial and other support to pregnant and post-partum women living with HIV (WLHIV), which has been shown to enhance maternal-infant outcomes in the prevention of mother-to-child transmission of HIV (PMTCT). Our objective was to assess the acceptability of mentor mothers as a PMTCT intervention, and to explore opinions on mentor mother program composition and delivery among stakeholders in NorthCentral Nigeria.

Methods: We conducted nine focus group discussions and 31 in-depth interviews with 118 participants, including WLHIV, pregnant women, male partners, health workers, traditional birth attendants, community leaders, PMTCT program implementers, and policymakers. Participants were purposively recruited from health facilities and surrounding communities in the Federal Capital Territory and Nasarawa State. Transcripts were manually analysed using a Grounded Theory approach, where theory was derived from the data collected.

Results: Most participants were female $(n=78,67 \%)$, and married $(n=110,94 \%)$. All participant groups found mentor mothers acceptable as women providing care to pregnant and postpartum women, and as WLHIV supporting other WLHIV. Mentor mothers were uniquely relatable as role models for WLHIV because they were women, living with HIV, and had achieved an HIV-negative status for their HIV-exposed infants. Mentor mothers were recognized as playing major roles in maternal health education, HIV treatment initiation, adherence, and retention, HIV prevention for male partners and infants, and couple HIV disclosure. Most WLHIV preferred to receive mentor mothers' services at health facilities rather than at home, due to concerns about HIV-related stigma and discrimination through association with mentor mothers. Key mentor mother needs were identified as training, remuneration, and validation as lay health workers.
\end{abstract}

Conclusions: Mentor mothers are an acceptable PMTCT intervention among stakeholders in North-Central Nigeria. However, stigma and discrimination for both mentor mothers and their clients remain a critical challenge, and mentor mother needs such as training, pay, and a sustainably supported niche in health systems require focused attention.

*Correspondence: nsamagudu@ihvnigeria.org

†Llewellyn J. Cornelius and Nadia A. Sam-Agudu are Co-senior authors.

${ }^{2}$ International Research Center of Excellence, Institute of Human Virology

Nigeria, Abuja, Nigeria

Full list of author information is available at the end of the article

(C) The Author(s) 2021. Open Access This article is licensed under a Creative Commons Attribution 4.0 International License, which permits use, sharing, adaptation, distribution and reproduction in any medium or format, as long as you give appropriate credit to the original author(s) and the source, provide a link to the Creative Commons licence, and indicate if changes were made. The images or other third party material in this article are included in the article's Creative Commons licence, unless indicated otherwise in a credit line to the material. If material is not included in the article's Creative Commons licence and your intended use is not permitted by statutory regulation or exceeds the permitted use, you will need to obtain permission directly from the copyright holder. To view a copy of this licence, visit http://creativecommons.org/licenses/by/4.0/. The Creative Commons Public Domain Dedication waiver (http://creativeco mmons.org/publicdomain/zero/1.0/) applies to the data made available in this article, unless otherwise stated in a credit line to the data. 
Trial registration: Clinicaltrials.gov registration number (NCT 01936753), registered on September 3, 2013 (retrospectively registered).

Keywords: Mentor mothers, Expert mothers, Peer support, Counseling, HIV, PMTCT, Nigeria

\section{Background}

The risk of mother-to-child transmission of HIV (MTCT) can approach elimination if pregnant women are able to access quality, comprehensive prevention of MTCT (PMTCT) services. These services include antenatal care (ANC) that offers and facilitates maternal HIV testing early in pregnancy, prompt uptake of lifelong antiretroviral therapy for women who test positive, infant antiretroviral prophylaxis, early infant diagnosis, and support services to promote maternal and infant adherence to care and treatment [1-3].

In 2019, an estimated 150, 000 children acquired HIV in utero, at birth or while breastfeeding in 23 UNAIDS focus countries which had high numbers of children, adolescents and women living with HIV (WLHIV) [2]. These 23 focus countries include 21 African countriesof which Nigeria is one- which together account for $84 \%$ of the global number of pregnant WLHIV and $81 \%$ of children under 15 years who were living with HIV in 2019 [2].

As a high HIV-burden country, Nigeria has much ground to cover in its progress towards elimination of MTCT (eMTCT) among the nearly 100,000 HIV-exposed infants born annually [2]. The national PMTCT program started in 2001/2002 at six tertiary health facilities; by 2018, these services, supported mainly by the US President's Emergency Plan for AIDS Relief (PEPFAR) and the Global Fund Against Tuberculosis, AIDS and Malaria, had expanded to nearly 6,500 health facilities across the country [4]. Despite the impressive scale-up of free-to-user HIV services, HIV treatment coverage among pregnant WLHIV in Nigeria was only $43 \%$ in 2019 , compared to the $88 \%$ average among the UNAIDS focus countries [2]. With an early infant diagnosis coverage of only $27 \%$, Nigeria ranked $16^{\text {th }}$ out of the 20 African eMTCT-focus countries in the same year [2]. The MTCT rate at six weeks post-delivery and from breastfeeding was 13\% and $9 \%$ respectively, for an overall $22 \%$ MTCT rate in Nigeria [2]. These estimates are far above the UNAIDS elimination targets of $2 \%$ and $5 \%$ MTCT rate among non-breastfed and breastfed infants, respectively [2]. Demand-side economic and social barriers (including funds for transportation, hidden user fees, and gender power dynamics) perpetuate low access to, and patronage of ANC and health facility delivery, two major platforms for PMTCT service delivery, contributing to unacceptably low HIV treatment coverage rates in spite of available services [5-8]. As a result, Nigeria alone accounted for approximately $15 \%$ of vertically-infected children living with HIV born globally in 2019 [2].

Several studies have shown that peer supporters and similar lay health workers who provide psychosocial and other support to pregnant and post-partum WLHIV enhance uptake of PMTCT services, which facilitate maternal viral suppression and infant HIV-free survival [9-12]. These lay peer supporters (also known as expert clients/patients/mothers or mentor mothers (MM)) counsel and guide other WLHIV through interactions at the health facility, home and/or other community locations $[13,14]$. The pioneering South African mothers2mothers $(\mathrm{m} 2 \mathrm{~m})$ PMTCT peer support program is now operating in 10 African countries; one in West Africa and the rest in East and southern Africa [14]. Similar models have been implemented in national PMTCT programs in many other African countries, often with significant funding from external donors [15-17].

While there is a growing body of literature on the impact of MM in PMTCT across sub-Saharan Africa [9$11,13,18]$, few studies have assessed the acceptability of these behavioral interventions among their target population (WLHIV) and other stakeholders [19]. These data are particularly lacking in the West and Central African region, where PMTCT achievements are lagging behind the rest of the continent [20].

The objective of this study, therefore, was to add to this growing body of knowledge specifically from West Africa, by assessing the acceptability of MM peer support as a PMTCT intervention among WLHIV and diverse groups of stakeholders in Nigeria. We further explore the opinions and experiences of participants regarding the wider PMTCT program, to identify barriers and facilitators to access and uptake of services, to guide MM program design and delivery.

\section{Methods \\ Study design and setting}

This qualitative formative study was conducted between December 2012 and April 2013, and was nested within the INSPIRE MoMent (Mother Mentor) study [21]. MoMent was a PMTCT Implementation Research study implemented in North-Central Nigeria between 2012 and 2017. With a prospective cohort design, the study evaluated the impact of a structured MM intervention on 
maternal retention and infant presentation for early HIV diagnosis [21-23]. MoMent was conducted at 20 rural and semi-rural primary health centres in the Federal Capital Territory and Nasarawa State in North-Central Nigeria. At the time of the study, rural and urban antenatal HIV prevalence in the Federal Capital Territory were $5.0 \%$ and $6.1 \%$, respectively; and for Nasarawa state, $9.0 \%$ and $5.0 \%$, compared to the national figures of $1.8 \%$ and $3.2 \%$, respectively [24].

\section{Study population and recruitment procedures}

We conducted focus group discussions (FGDs) and indepth interviews (IDIs) with pregnant and non-pregnant women, including ANC attendees, MMs and $\mathrm{m} 2 \mathrm{~m}$ support group members. We also interviewed male partners, health workers, traditional birth attendants (TBAs), community leaders and PMTCT program implementers and policymakers [21]. FGDs allowed for an exploration of target group opinions and experiences. IDI participants were interviewed for their individual opinions in the context of their individual expertise and experiences. Participants were drawn from health facilities and surrounding communities within MoMent's proposed study locations in rural Federal Capital Territory and Nasarawa State.

Eligible participants were recruited through purposive sampling and were $\geq 18$ years old and living, working and/or accessing health services in the study communities. Health workers and community gatekeepers identified potential participants at health facilities or from the community, as PMTCT "users," "facilitators" and "providers." Interested participants gathered at agreed-upon interview locations, which were private spaces at health facilities or in the study community. Multilingual study staff explained the study and objectives to all participants in English or their preferred local language, and obtained individual written informed consent from each participant. Participants who could not read or write provided witnessed thumbprints.

\section{Data collection}

Prior to each session, an interviewer administered survey was used to capture participants' socio-demographic data, including age, marital status and religion. Two trained research staff facilitated each audio-recorded FGD and IDI using an interview guide; focus groups additionally had an observer to record non-verbal cues. At least one facilitator was multilingual (in English, pidgin English and/or Hausa, the dominant language in the study setting). The guides explored knowledge of/ experiences with peer support, and its acceptability for pregnant women in general and for PMTCT in particular (see Additional Files 1, 2, 3, 4, 5 and 6). FGDs lasted 1.5 to $2 \mathrm{~h}$ and IDIs approximately $45 \mathrm{~min}$.

\section{Data transcription and analysis}

All FGDs and IDIs were transcribed verbatim; where necessary, they were translated into English from pidgin English or Hausa by the same staff who facilitated the interviews. Our theoretical approach to qualitative analysis was Grounded Theory, where we derived theory from the data, rather than applying preformed theory to the data $[25,26]$.

All transcripts were manually analyzed using the constant comparison method of Grounded Theory [26], in a thematic analysis approach [27]. The analysis team comprised a total of ten paired and trained research staff (including MAM, SE, NASA and LJC and the rest of the facilitator team). In initial coding, each transcript was hand-coded by one pair of analysts, who individually reviewed their assigned transcript line-by-line to identify recurring words and phrases as codes. Similar inductive codes were then collated into a list by each pair of analysts, according to identified patterns. Thereafter, in group analysis, these lists of codes were categorized into a coding tree, with parent (main) codes under which related subcategory codes were arranged [28]. This list was used to conduct a group iterative analysis, during which analysts' interpretations were triangulated and themes elicited until thematic saturation was achieved and no more additional interviews were needed [29]. At this point, the listed codes did not identify any additional themes, and no more emerging codes or themes were derived from analysed transcripts. AO additionally analysed each transcript independently. We have provided supplementary information using the Consolidated Criteria for Reporting Qualitative Research (COREQ) checklist [30] (See Additional File 7).

\section{Results}

We conducted nine FGDs and 31 IDIs with a total of 118 participants, including 20 pregnant women, 46 WLHIV (MMs and $\mathrm{m} 2 \mathrm{~m}$ support group members), 30 male partners, 17 health providers, and five community leaders (Table 1). Most participants were female $(n=78,67 \%)$, and married $(n=110,94 \%)$. Three recruited participants did not show up for interviews (one for an m2m FGD; two for MM FGDs); one MM was unable to participate due to a scheduling conflict, and information on the other two no-shows is not available.

\section{Overall acceptability of mentor mothers among stakeholders}

There was consensus among all categories of respondents that MMs were acceptable, as women providing peer support to pregnant women, and as WLHIV who support other WLHIV. 
Table 1 FGD and IDI participant characteristics

\begin{tabular}{|c|c|c|c|c|c|c|}
\hline $\begin{array}{l}\text { Participant Group } \\
\text { (N groups) }\end{array}$ & $\begin{array}{l}\text { Number of } \\
\text { Participants }\end{array}$ & $\begin{array}{l}\text { Female } \\
\text { n (\%) }\end{array}$ & Age Range (Years) & $\begin{array}{l}\text { Education } \\
\mathrm{n}(\%)\end{array}$ & $\begin{array}{l}\text { Married } \\
\mathrm{n}(\%)\end{array}$ & $\begin{array}{l}\text { Religion } \\
\mathrm{n}(\%)\end{array}$ \\
\hline \multicolumn{7}{|c|}{ Focus Group Discussions (9 groups, $\mathrm{N}=87$ participants) } \\
\hline \multicolumn{7}{|c|}{ PMTCT Users (Women, including WLHIV) } \\
\hline ANC clients (2) & 20 & $57(100.0)$ & $20-38$ & \multirow{3}{*}{$\begin{array}{l}\text { < Secondary: } 18(31.6) \\
\text { Z Secondary: } 36(63.1) \\
\text { No response: } 3(5.3)\end{array}$} & \multirow[t]{3}{*}{$54(94.7)$} & \multirow{3}{*}{$\begin{array}{l}\text { Christian: } 39 \text { (68.4) } \\
\text { Muslim: } 18 \text { (31.6) }\end{array}$} \\
\hline m2m group members ${ }^{\mathrm{a}}(2)$ & 19 & & & & & \\
\hline Mentor Mothers ${ }^{\mathrm{a}}(2)$ & 18 & & & & & \\
\hline \multicolumn{7}{|l|}{ РMTCT Facilitators } \\
\hline Male partners ${ }^{\mathrm{b}}(3)$ & 30 & $0(0.0)$ & $33-87$ & $\begin{array}{l}\text { < Secondary: } 12(40.0) \\
\geq \text { Secondary: } 18(60.0)\end{array}$ & $30(100.0)$ & $\begin{array}{l}\text { Christian: } 12(40.0) \\
\text { Muslim: } 18 \text { (60.0) }\end{array}$ \\
\hline \multicolumn{7}{|l|}{ In-Depth Interviews $(\mathrm{N}=31)$} \\
\hline \multicolumn{7}{|l|}{ РМТCT Users $(n=9)$} \\
\hline $\begin{array}{l}\text { m2m group members } \\
\text { Mentor Mothers }^{\mathrm{a}}\end{array}$ & $\begin{array}{l}4 \\
5\end{array}$ & $9(100.0)$ & $21-50$ & $\begin{array}{l}\text { < Secondary: } 1 \text { (11.1) } \\
\geq \text { Secondary: } 8 \text { (88.9) }\end{array}$ & $9(100.0)$ & $\begin{array}{l}\text { Christian: } 8 \text { (88.9) } \\
\text { Muslim: } 1 \text { (11.1) }\end{array}$ \\
\hline \multicolumn{7}{|l|}{ PMTCT Providers $(n=17)$} \\
\hline $\begin{array}{l}\text { Traditional birth attendants } \\
\text { Health workers } \\
\text { Govt. officials/policy-makers } \\
\text { Program implementers }\end{array}$ & $\begin{array}{l}4 \\
4 \\
3 \\
6\end{array}$ & $12(70.6)$ & $21-50$ & $\begin{array}{l}\text { < Secondary: } 2 \text { (11.8) } \\
\geq \text { Secondary: } 15 \text { (88.2) }\end{array}$ & $14(82.4)$ & $\begin{array}{l}\text { Christian: } 14 \text { (82.4) } \\
\text { Muslim: } 3 \text { (17.6) }\end{array}$ \\
\hline \multicolumn{7}{|l|}{ PMTCT Facilitators $(n=5)$} \\
\hline Community leaders ${ }^{c}$ & 5 & $0(0.0)$ & $21-51+$ & $\begin{array}{l}\text { < Secondary: } 0(0.0) \\
\geq \text { Secondary: } 4(80.0) \\
\text { No response: } 1 \text { (20.0) }\end{array}$ & $4(80.0)$ & $\begin{array}{l}\text { Christian: } 1 \text { (20.0) } \\
\text { Muslim: } 4 \text { (80.0) }\end{array}$ \\
\hline Grand Total & 118 & $78(66.1)$ & $20-87$ & $\begin{array}{l}\text { < Secondary: } 33(28.0) \\
\geq \text { Secondary: } 81(68.6) \\
\text { No response: } 4(3.4)\end{array}$ & $111(94.1)$ & $\begin{array}{l}\text { Christian: } 74 \\
(62.7) \\
\text { Muslim: } 44 \text { (37.3) }\end{array}$ \\
\hline \multicolumn{7}{|c|}{ FGD focus group discussion, IDI in-depth interview, PMTCT prevention of mother-to-child transmission of HIV, ANC antenatal care, $m 2 m$ mothers $2 m o t h e r s$} \\
\hline
\end{tabular}

\section{PMTCT users: pregnant and non-pregnant women living and not living with HIV}

Peer support was acceptable to women in general, and especially first-time mothers, because they could receive psychosocial support and experiential advice on pregnancy and infant care-related issues.

Like we that have not gotten pregnant before; it might be good if I have somebody like that, who will talk to me and make me feel relaxed. (Primigravid woman, FGD ANC 1)

For WLHIV, MMs were healthy and had HIV-negative children, and were therefore role models for optimal maternal health and having an HIV-free infant.

It would encourage me [to have an MM]. She would be encouraging me to do the same thing that she did during her pregnancy. (WLHIV 1, IDI)

Without them (MMs), we will not know how to take our drugs or take care of our babies. (m2m 1, IDI)
PMTCT providers: Healthcare workers, including traditional birth attendants, program implementers and policy-makers Health workers and other providers were accepting of peer support in PMTCT because of the positive impact of MMs on WLHIV outcomes - results that sometimes, health workers were unable to achieve.

Most of the time when a woman is [HIV-] positive, no matter how the health worker advises her, she doesn't accept it like from the mentor mothers, because the mentor mother will tell them how they were successful through PMTCT. So mentor mothers are very, very important. (State Ministry of Health staff, IDI)

They [MMs] are useful because they encourage women to come to the hospital. (TBA 1, IDI)

Some [pregnant WLHIV] will say [to health workers], "Ah Aunty, you don't understand what I'm passing through.' But if the mentor mothers, those that have passed through the same thing, talk to her, they get relief. So they [MMs] help us. (Health 
worker 1, IDI)

They will allay the fear of the newly diagnosed positive patient; knowing that she has been in your shoes, she has passed through it, and gave birth to children [who] are HIV-negative. It will really serve as a motivation for the mothers. (Program Implementer 1, IDI)

\section{PMTCT facilitators: male partners and community leaders}

Male partners were favourably disposed towards peer support for pregnant women, regardless of the woman's HIV status.

The services these ladies [MMs] are going to do is similar to the ones our mothers would have been doing for our wives if our wives were to be living with them. (Male partner, FGD1)

They [MMs and WLHIV] will both understand themselves from experience, being they are both HIV-positive. They will communicate better. (Male partner, FGD1)

Based on MMs' experiences, male partners for the most part encouraged and supported their HIV-positive partners to work as MMs, regardless of the man's own HIV status. However, stigma was a concern:

The husband has no problem; he only told her [MM] that she should ensure that she is accepted where she goes for the visit. And that she should not enter any house where they don't accept her. (MM, FGD2)

Other male partners, however, did not approve of their partners' work as MMs; some withdrew financial and material support.

Since she started working as a mentor mother, the husband has stopped supporting her with little things that she is in need of, like soap and household items. And during their meetings, other women usually complain that their husbands no longer provide for them. (MM, FGD2)

Community leaders also expressed the need for mentor mothers and were in support of them working in their communities:

It is not somebody new that is coming to the community to tell them [women and their families] "Do this, do this" because if somebody is coming from outside, somebody that they don't know, they may not be convinced... so the best thing is to use such, you know; mentors, such people from the community to talk to the community people. (Community leader 1) (Mentor mothers will be helpful) because they [MM] have been trained and they are participat- ing already [in PMTCT] and because they volunteer to participate. The women understand them and they are used to them and the mentor mothers have gained knowledge as a result of the training they received and they can use their knowledge to create more awareness. (Community leader 2)

\section{Role of mentor mothers}

WLHIV who were MMs and $\mathrm{m} 2 \mathrm{~m}$ group members spoke from their personal experiences of what MM roles were and/or should be.

\section{Positive role model and confidante}

As WLHIV who have utilised PMTCT services with successful outcomes, MMs are uniquely positioned to model positive HIV prevention, treatment uptake, adherence and retention behaviors for other WLHIV to emulate.

When we do our post-test counselling, we usually tell them [WLHIV] that we are in the same shoes as they are. They can't believe it. When we tell them that we are also positive, they will say that it is a lie. (MM, FGD2)

Three main characteristics make MMs uniquely relatable and credible to their WLHIV clients. First, they are women, and thus understand the gender-related challenges of life, health, and healthcare in the community. Second, MMs are also living with HIV and therefore share the same lived experiences. Third, MMs have successfully navigated the PMTCT cascade resulting in an HIV-free infant, so they can provide guidance to other WLHIV from these personal experiences. Ultimately, MMs play roles for WLHIV that cannot be played by health workers, male partners or other women not living with HIV.

When we came for the [m2m] meeting it was all women, and two people were here to tell us many things about this mother-to-child stuff. So you feel more free discussing with your fellow woman who is positive within the circle. ( $m 2 m$ member, FGD1)

They counsel you as direct experienced persons... telling you what they passed through. It worked for them so it will work for you if you copy it. (WLHIV 2, IDI)

As a mentor mother, you can talk the way they [WLHIV] will understand. But as a nurse, if you tell them something, they will be like, "don't mind that nurse, she doesn't know what I'm passing through". (WLHIV 3, IDI) 


\section{Emotional and psychosocial support}

The first resource a newly HIV-diagnosed pregnant woman often encounters is an MM, during one-on-one post-test counselling [13]. This initial encounter provides critical emotional and psychosocial support to help the client understand and deal with the ensuing anxiety, fears and concerns following a positive HIV diagnosis.

Most of them [newly-diagnosed pregnant women] respond by worry. So we usually calm them down and tell them that we have been in this situation and most of them calm down; they cooperate with us and accept the information given to them, including how they can get the drugs so that eventually their children will not be able to contract HIV. (MM, FGD2)

MMs are also instrumental in forming $\mathrm{m} 2 \mathrm{~m}$ support groups for WLHIV. They facilitate regular group meetings during which they provide health education, psychosocial support, and HIV treatment literacy.

During health education, they [MMs] educate the mothers. (Health worker 2, IDI)

After the post-test counselling we enrol the [HIVpositive] person into the mother-to-mother support group. So whenever they are having meetings, we call them. (Health worker 3, IDI)

\section{HIV prevention for women and their male partners}

MMs play a key role in HIV prevention through preand post-test counselling for pregnant women during ANC clinics. Prevention messages include breastfeeding and safe infant feeding options to prevent infant HIV infection. For women who test HIV-positive, MMs also encourage and assist with male partner HIV testing and couples' HIV status disclosure.

When the results come out, she [nurse] hands them over to me. I know how to tell a positive woman to bring her husband. I will tell you to tell the man that they want to see him in antenatal [clinic]. Then I will know strategies to use, and those strategies have been working. This month we counselled twelve [men], and out of those twelve, four were positive, and I know how I've tackled those that come out positive. (MM FGD1)

\section{Support for women throughout the PMTCT cascade}

Women who test positive are encouraged by MMs to initiate HIV treatment during post-test counselling. MMs also follow up on WLHIV through phone calls, text messaging and/or home visits to encourage adherence, keeping clinic appointments and attending support group meetings, which ultimately facilitate retention and sustained viral suppression.

At times they [newly-diagnosed WLHIV] will not listen to us. But when they [MMs] tell them, "See, I have gone through it and I'm breastfeeding my baby and the baby is HIV-negative," then most of them that refused will start taking the drugs. (TBA 2, IDI) [During home visits], we remind them about their drug, discuss their well-being and then clinic attendance if they forgot. (MM, FGD2)

[MMs] are very effective in tracking [clients who missed appointments]. (Program implementer 2, IDI)

Mentor mothers follow them up so that they bring them back so that they especially receive nevirapine for the babies. (Program implementer 3, IDI)

\section{Mentor mother recruitment}

The $\mathrm{m} 2 \mathrm{~m}$ support group is a natural and convenient platform for recruiting MMs. Health workers often select MMs based on their demonstrated leadership and commitment in $\mathrm{m} 2 \mathrm{~m}$ support groups and consistent clinic attendance and treatment adherence.

The matron in charge saw me coming all the time to collect my drugs. So she asked me if I could continue mentoring other mothers and bringing people to the hospital for testing. (MM FGD2)

The matron of the hospital talked to me. I told her I have a diploma. She said, 'Can't you come and give health talks to these women since you can talk? That is how I started coming out and giving health talks to those women. (MM, FGD1)

Members of support groups may also indicate their interest to work as MMs.

When we started the support group, she [nurse] announced that we need mentor mothers, and any mother that passed through PMTCT, who is willing to do it, should come and join. So I said I will join because I want to share my experience with other women. (MM FGD1)

While MMs were regarded as a welcome community resource, there were reservations about recruiting MMs to work in their own community, due to stigma.

Because [MMs] live with them in the community, [WLHIV] won't have any inferiority complex when they are talking to [MMs]. (Community leader 1, IDI)

Women will not agree to be mentor mothers in their 
community because that would be the same as declaring that they are HIV-positive. (TBA 2, IDI)

Other personal qualities of potential MMs include being approachable, possessing good interpersonal and leadership skills, resilience, and acceptance of their own HIV-positive status as a demonstration of overcoming (self)-stigma.

From the support group members, when they see a very strong somebody with potential of being a leader, they can recruit the person into the mentor mother program. (MM FGD1)

The way I took the news, maybe [the nurse] was thinking I will break down and start crying, but I took it in good faith. Then, she talked to me about being a mentor mother. (MM FGD1)

MMs were expected to be willing to share their personal PMTCT experiences with other women, and disclose their HIV status to their clients.

From $m 2 m$ [support groups], we choose those that are willing to share their ideas, challenges and experience to be a role model and help use themselves as a testimony. (MM FGD1)

Self-disclosure was particularly important, as some clients had reported that their MMs did not directly disclose their HIV status to them, if at all.

She [MM] did not disclose her status to me and I did not know she was hiding it. It was the day we came for a [m2m] meeting here, after about a year plus, that I came to know. (M2M FGD1)

\section{Facility versus community-based peer support}

WLHIV overwhelmingly preferred receiving MM support at facilities as opposed to home visits, because of the fear of being "outed" as living with HIV. While MMs themselves were not opposed to conducting home visits, they reported that the majority of their clients preferred facility-based support. This was due to the fear of association with MMs, who were known in the community to be HIV-positive.

Out of 100, I think it is only 25\% that allow us to go to their house. $75 \%$ don't want us to come because maybe they're having partners [co-wives] at home and the partners maybe have not been tested, and maybe the man too, is a kind of a man that, when you tell him something, he will be talking to everyone about it. (MM FGD2)
Women who did not want home visits preferred mentoring by telephone.

Honestly, when they know that you are "this" [HIVpositive], they don't want you to come to their house. So normally we contact them with phone. (MM, FGD 2)

A few WLHIV, however, preferred home visits because they did not want to be seen in the clinic, as frequent clinic visits could increase the risk of revealing their HIVpositive status.

Some will feel that since she has HIV, people will know, and she doesn't want to be coming [to the clinic] so that people will see her. She will prefer to call somebody to come home and check her. (ANC FGD2)

The underlying reason for women choosing to interact with MMs at home or at the facility appeared to be perceived stigma, and fear of lack of privacy and confidentiality. The risk of being gossiped about by neighbours also varied with place of residence, being perceived more common in rural areas and places where people lived in proximity.

It depends on the environment you live in. They have neighbours all round. And you know some women are fond of gossiping. So if they get to know about something like that, the way they will talk about the person....So I don't really think it's ok [for home visits]. (ANC FGD1)

\section{Duration of mentor mother support}

Participants suggested that MMs provide support to clients throughout pregnancy, delivery, and post-partum.

Let me say: throughout my pregnancy and after my delivery-maybe one or two months, they [MM] can stay with me. (ANC FGD1)

She should be supported for six months after delivery. (Male partner FGD1)

Some women felt that the duration of support should be inversely proportional to parity, so that primigravid or primiparous women would receive support for a longer period.

It depends on which pregnancy you are carrying [ie parity]. (ANC FGD1) 


\section{Program and material support for mentor mothers Training}

Specific and tailored training for MM on HIV and communication skills were considered necessary to enable them to function properly.

We the mentor mothers, if you [PMTCT program implementers] will set a kind of training for us, we will so much appreciate it. (MM FGD2)

We also need training. We have to know how to talk to [the] husbands. (MM FGD1)

\section{Financial support}

Adequate funding-at least to cover transportation costs for home visits, support group meetings, phone calls and text messages to clients-were needed as fair compensation and to incentivize MMs' performance.

Mentor mothers [should] be provided with a token, because they are the people who go to the villages. (State Ministry of Health 1, IDI)

If [an MM] can be employed, she knows that she is being paid fully for the work she is doing. She will not joke with it. (State Ministry of Health 2, IDI)

We have the mentor mothers who track our lost-to follow-up within the community. We usually give them an incentive monthly, and money for recharge cards. (Program Implementer 2, IDI)

\section{Identification cards and attire}

Some MMs mentioned the need for identification cards and/or special attire for work.

Our greatest challenge in going into the community is the issue of ID cards, because people want to know who exactly we are before going into their compound or visiting them at home. (MM, FGD1)

However, others felt these would increase HIV stigma and discrimination in the community.

How can you wear an ID with HIV on it and visit somebody? The people within that compound will know that the particular person that you came to visit has HIV. (MM, FGD1)

Similarly, some respondents stressed that attire that easily identified the MM as a person living with HIV or working with people living with HIV should also be avoided.

Even this our shirt, some people will say if you are coming to my house don't wear anything that will display HIV. (MM FGD1)

Figure 1 presents the above emerging themes and their interrelationships as derived from our thematic analysis.

\section{Application of formative research findings to study design} Amenable findings and lessons learned were applied to the prospective cohort study design. These focused largely on the design and delivery of the MM

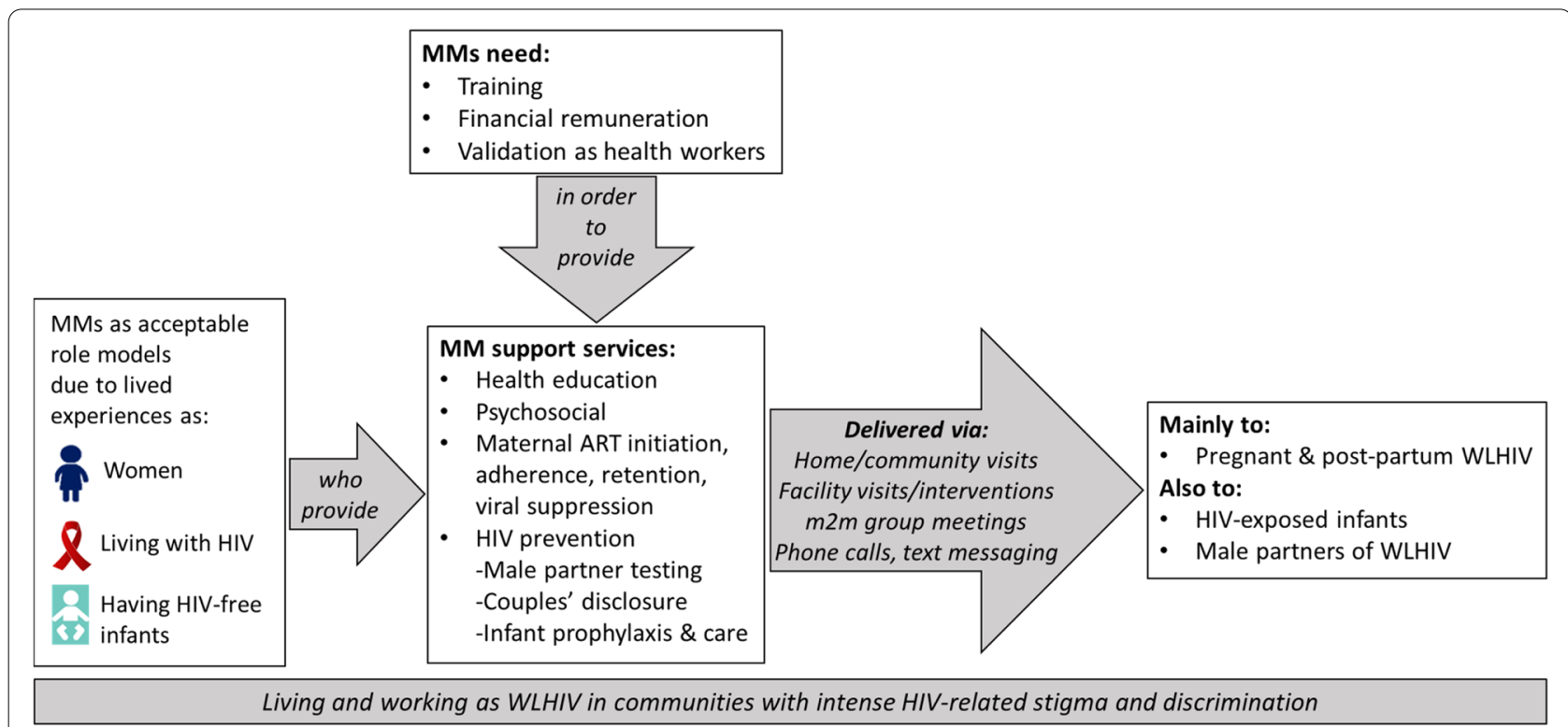

Fig. 1 Emerging themes on mentor mother peer support to women living with HIV 


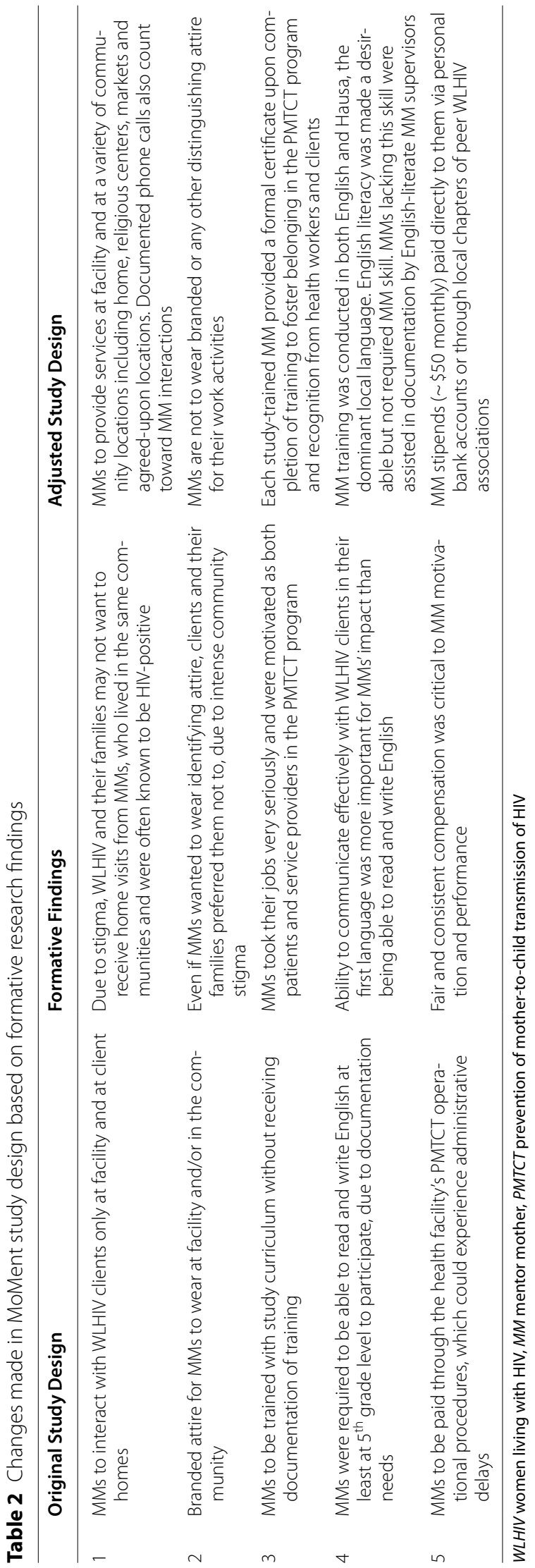


intervention, and included changes in $\mathrm{MM}$ selection requirements, locations for client interactions, attire, certification of MM training, and modalities for paying stipends (Table 2).

\section{Discussion}

Our findings indicate that MMs were acceptable to WLHIV and other stakeholders in our study setting. Similar findings have been reported from Kenya [19], and among low-income women in the United States [31], and England [32]. A recurring phrase in our study was that MMs 'were in the same shoes' as their WLHIV clients. This similarity of lived experiences and personal demonstration of successful PMTCT outcomes make MMs relatable, credible role models [31-35].

MMs facilitate key services along every step of the PMTCT cascade [13, 33, 34, 36-38]. Similar to prior studies, we found that keeping exposed infants HIV-free was a particularly strong motivator for WLHIV to access and remain in PMTCT care $[32,33,39,40]$. MMs project relatability and empathy to further motivate WLHIV to access and stay retained in care, which formal health workers are sometimes unable to do. We have previously documented the narratives of WLHIV (including MMs) regarding negative attitudes of health workers in Nigeria [5, 41], and McLeish (2016) and Shroufi (2013) described empathy from MMs that WLHIV felt health workers did not possess or demonstrate [32, 34]. As with other African studies, our study respondents preferred MM support to last from pregnancy through several months post-partum [36], with lower-parity women receiving longer-term support than more experienced mothers.

Despite the overall acceptance of MM peer support, stakeholders echoed concerns about privacy and confidentiality during home or clinic visits from MMs, due to fear of inadvertent HIV-status disclosure and the ensuing stigma and discrimination. This has also been reported from Kenya and Malawi [33, 36, 42]. Such concerns factor into WLHIVs' preferences for home, phone, or clinicbased support, and whether recruited MMs should work in the communities where they live [19]. As also reported from Kenya, clients also did not want MM to wear 'HIVidentifying' attire or identification cards $[19,36]$.

Similar to other studies, we identified essential MM qualities such as good communication skills, empathy, friendliness and willingness to share their own PMTCT and lived HIV experiences. The finding that some MMs did not disclose their status to their clients was unexpected and concerning. This is contrary to the assumption that all MMs had overcome (self)-stigma and were therefore willing and unafraid to disclose their HIV status. We have published detailed findings on MM nondisclosure from the same Nigerian study setting [43].

Another MM requirement was an explicitly expressed willingness to play this role. Simply possessing other desirable qualities was not enough to recruit an MM: she must also be enthusiastic and motivated to provide peer support. While this may seem obvious, implicit in this is the commitment to positive maternal, infant and family PMTCT outcomes and openness in sharing personal experiences, including a positive HIV status.

Public disclosure by MMs in community settings is a means of normalizing living with HIV - as these women reflect the overcoming of (self)-stigma and living healthy and fulfilled lives. Creating community awareness about the availability and impact of PMTCT interventions also contributes to removing the stigma around HIV. The overwhelming concern for privacy and confidentiality stemming from lived and observed stigma and discrimination echoed through discussions with all participant groups. The avoidance and/or mitigation of stigma would therefore impact on MM recruitment and all aspects of MM activities along the PMTCT cascade.

The recommendation for adequate MM compensation illustrates MM acceptability, and could promote program sustainability through improved lay worker satisfaction and performance $[41,44-48]$.

\section{Study strengths and limitations}

Our study strengths include the diversity of recruited stakeholders: WLHIV with and without prior MM experience, pregnant and non-pregnant women who had neither PMTCT nor MM experience, formal (health worker) and informal (TBA) maternal care providers, program implementers and policy makers, male partners, and community leaders. However, our findings are from North-Central Nigeria, and thus may not be generalizable to other Nigerian or African settings. The MoMent study did not focus on adolescent respondents $<18$ years, whose experiences may be different-both as PMTCT providers/peer supporters and PMTCT users. Thus, our study findings may not be applicable to this group. Lastly, it was evident that some participants in our study setting were already familiar with the concept of MMs in PMTCT programs. It is possible that the level of acceptability of this peer support intervention may have been different if there were little to no prior exposure to the concept among our participants.

\section{Conclusions}

This qualitative study provides insight regarding the local context for acceptability and application of PMTCT peer support in Nigeria. Findings informed the redesign of an MM intervention to better suit the needs 
and circumstances of WLHIV and communities in North-Central Nigeria, in order to facilitate improved health outcomes. Per our findings, lay maternal peer support plays a critical role in PMTCT and is acceptable to WLHIV and other stakeholders. It is important, however, to address pervasive issues around privacy, confidentiality, stigma and discrimination for both MMs and their clients. As highlighted by UNAIDS, inequalities, stigma and discrimination undermine efforts towards HIV epidemic control by contributing to increased vulnerability, limited access to care and treatment, HIV acquisition (including MTCT), and death from AIDS-related illnesses [49]. Failing to address these issues will continue to limit utilization of scaled-up, available PMTCT services. Lessons learned from implementation and additional research in West and Central Africa should further inform MM programs to support countries in addressing PMTCT gaps in this region. Finally, considerations are needed to create and sustain a niche for MMs in PMTCT and in general maternal-child health.

\begin{abstract}
Abbreviations
ANC: Antenatal care; eMTCT: Elimination of mother-to-child transmission of HIV; FGD: Focus group discussion; HIV: Human immunodeficiency virus; IDI: In-depth interview; MM: Mentor mother; m2m: Mothers2mothers; MTCT : Mother-to-child transmission of HIV; PMTCT: Prevention of mother-to-child transmission of HIV; TBA: Traditional birth attendant; UNAIDS: Joint United Nations Program on HIV/AIDS; WHO: World Health Organization; WLHIV: Women living with HIV.
\end{abstract}

\section{Supplementary Information}

The online version contains supplementary material available at https://doi. org/10.1186/s12884-021-04002-1.

Additional file 1. FGD guide for PMTCT users: pregnant women at antenatal care clinics.

Additional file 2. FGD guide for PMTCT users: women living with HIV (m2m and MMs) [43].

Additional file 3. FGD guide for PMTCT facilitators: male partners [8]. Additional file 4. IDI guide for PMTCT users.

Additional file 5. IDI guide for PMTCT providers (formal health workers, traditional birth attendants, government officials/policy-makers, program implementers).

Additional file 6. IDI questionnaire for PMTCT facilitators: community leaders.

Additional file 7. COREQ checklist.

\section{Authors' contributions}

AO performed analysis, drafted the manuscript, and conducted final review. MAM collected data, performed analysis, contributed to manuscript writing, and conducted final review. NT and TLJ contributed to manuscript writing and conducted final review. SE collected data, performed analysis, contributed to manuscript writing, and conducted final review. AJA collected data, contributed to manuscript writing and conducted final review. EA and HSG contributed to study design and manuscript writing, and conducted final review. LC conceptualized and designed the study, performed analysis, contributed to manuscript writing, and conducted final review. NASA conceptualized and designed the study, drafted the manuscript, performed analysis, and conducted final review. The authors read and approved the final manuscript.

\section{Funding}

The MoMent Nigeria study was funded by the World Health Organization through an award for the INtegrating and Scaling up PMTCT through Implementation REsearch (INSPIRE) initiative from Global Affairs Canada.

\section{Availability of data and materials}

All data generated or analyzed during this study are included in this published article (and its supplementary information files).

\section{Declarations}

\section{Ethics approval and consent to participate}

The study was approved by the Nigerian National Health Research Ethics Committee (NHREC/01/01/2007-12/04/2016); the Ethics Review Committee of the World Health Organization (WHO_RPC531), and the Institutional Review Boards of the University of Maryland Baltimore (HP-00069521) and the University of Georgia Athens (STUDY00003529). Individual written informed consent was sought and documented from each participant.

\section{Consent for publication}

Not applicable.

\section{Competing interests}

The authors declare that they have no competing interests.

\section{Author details}

${ }^{1}$ Research Consultant, Abuja, Nigeria. ${ }^{2}$ International Research Center of Excellence, Institute of Human Virology Nigeria, Abuja, Nigeria. ${ }^{3}$ Present address: Duke University School of Nursing, Durham, USA. ${ }^{4}$ Pediatric and Adolescent HIV Unit, Prevention, Care and Treatment Department, Institute of Human Virology Nigeria, Abuja, Nigeria. ${ }^{5}$ Present address: Elizabeth Glaser Pediatric AIDS Foundation, Abuja, Nigeria. ${ }^{6}$ Present address: Society for Family Health, Abuja, Nigeria. ${ }^{7}$ Department of Community Medicine, Equitable Health Access Initiative, Lagos, Nigeria. ${ }^{8}$ Department of Pediatrics, Faculty of Clinical Sciences, Obafemi Awolowo University, Ile-lfe, Nigeria. ${ }^{9}$ Africa Center of Excellence for Population Health and Policy, Bayero University, Kano, Nigeria.

${ }^{10}$ Continuous Quality Improvement Unit, Learning and Development Department, Institute of Human Virology Nigeria, Abuja, Nigeria. ${ }^{11}$ School of Social Work and College of Public Health, University of Georgia Athens, Athens, GA, USA. ${ }^{12}$ Institute of Human Virology and Department of Pediatrics, University of Maryland School of Medicine, Baltimore, USA.

Received: 13 February 2021 Accepted: 13 July 2021

Published online: 07 August 2021

\section{References}

1. Hamilton E, Bossiky B, Ditekemena J, Esiru G, Fwamba F, Goga AE, et al. Using the PMTCT Cascade to Accelerate Achievement of the Global Plan Goals. J Acquir Immune Defic Syndr 1999. 2017;75(Suppl 1):S27-s35.

We acknowledge the enabling support of the Federal Capital Territory Health and Human Services Secretariat, the Nasarawa State Ministry of Health, and the Nigeria Federal Ministry of Health in the planning and implementation of this study. We appreciate the work of MoMent study staff and personnel of the Institute of Human Virology Nigeria and the Clinton Health Access Initiative in planning, data collection and analysis. Lastly, we sincerely thank all study participants for enthusiastically sharing their time, insights and experience.
2. UNAIDS. Start Free Stay Free AIDS Free-2020 Report 2020 [Available from: https://www.unaids.org/sites/default/files/media_asset/start-free-stayfree-aids-free-2020-progress-report_en.pdf. Accessed 30 Sept 2020.

3. UNICEF. Key Considerations for Programming and Prioritization. Going the 'Last Mile' to eMTCT: A road map for ending the HIV epidemic in 
children 2020 [Available from: http://www.childrenandaids.org/Last-Mileto-EMTCT. Accessed 23 June 2021.

4. National Agency for the Control of AIDS (NACA) Nigeria. National AIDS Spending Assessment, 2015 to 2018 Abuja, Nigeria: Federal Government of Nigeria; 2019 [Available from: https://naca.gov.ng/nasa-report-2019/. Accessed 1 July 2021.

5. Cornelius LJ, Erekaha SC, Okundaye JN, Sam-Agudu NA. A Socio-Ecological Examination of Treatment Access, Uptake and Adherence Issues Encountered By HIV-Positive Women in Rural North-Central Nigeria. J Evid Inf Soc Work. 2018;15(1):38-51.

6. Olakunde BO, Adeyinka DA, Olakunde OA, Ozigbu CE, Ndukwe CD, Oladele T, et al. Correlates of antiretroviral coverage for prevention of mother-to-child transmission of HIV in sub-Saharan Africa. AIDS Care. 2019;31(10):1255-60.

7. Adeyinka DA, Agogo EA, Ozigbu CE, Aboje S, Anyaike C, Asadu EC, et al. Missed opportunities in the prevention of mother-to-child transmission of HIV infection: experience from a national programme in Nigeria. Int J STD AIDS. 2016;27(14):1338-41.

8. Al-Mujtaba M, Sam-Agudu NA, Torbunde N, Aliyu MH, Cornelius LJ. Access to maternal-child health and HIV services for women in NorthCentral Nigeria: A qualitative exploration of the male partner perspective. PLoS One. 2020;15(12):e0243611.

9. Ambia J, Mandala J. A systematic review of interventions to improve prevention of mother-to-child HIV transmission service delivery and promote retention. J Int AIDS Soc. 2016;19(1):20309.

10. Mwai GW, Mburu G, Torpey K, Frost P, Ford N, Seeley J. Role and outcomes of community health workers in HIV care in sub-Saharan Africa: a systematic review. J Int AIDS Soc. 2013;16(1):18586.

11. Geldsetzer P, Yapa HM, Vaikath M, Ogbuoji O, Fox MP, Essajee SM, et al. A systematic review of interventions to improve postpartum retention of women in PMTCT and ART care. J Int AIDS Soc. 2016;19(1):20679.

12. Haberer JE, Sabin L, Amico KR, Orrell C, Galarraga O, Tsai AC, et al. Improving antiretroviral therapy adherence in resource-limited settings at scale: a discussion of interventions and recommendations. J Int AIDS Soc. 2017:20(1):1-15.

13. Cataldo F, Sam-Agudu NA, Phiri S, Shumba B, Cornelius LJ, Foster G. The Roles of Expert Mothers Engaged in Prevention of Mother-to-Child Transmission (PMTCT) Programs: A Commentary on the INSPIRE Studies in Malawi, Nigeria, and Zimbabwe. J Acquir Immune Defic Syndr 1999. 2017;75(Suppl 2):S224-32.

14. mothers 2 mothers. mothers 2 mothers 2020 [Available from: https:// www.m2m.org/. Accessed 26 June 2021.

15. Management Sciences for Health. Report: The Role of Mother Mentors in Supporting HIV-Positive Mothers 2014 [Available from: https://www. msh.org/sites/default/files/or_march_2014.pdf. Accessed 26 June 2021.

16. PEPFAR. The PEPFAR Solutions Platform. 2018 [Available from: https:// www.pepfarsolutions.org/solutions/2018/12/19/cfm-improvingmother-baby-pair-retention-in-interated-maternal-and-child-healthand-hiv-services-in-eswatini. Accessed 26 June 2021.

17. The Global Fund. Audit Report: Global Fund Grants in the Republic of South Sudan. 2019. [Available from: https://www.theglobalfund.org/ media/8983/oig_gf-oig-19-021_report_en.pdf?u=637233413370000 000. Accessed 26 June 2021.

18. Nachega JB, Sam-Agudu NA, Mofenson LM, Schechter M, Mellors JW. Achieving Viral Suppression in 90\% of People Living with HIV on Antiretroviral Therapy in Low- and Middle-Income Countries: Progress, Challenges, and Opportunities. Clin Infect Dis. 2018;66(10):1487-91 . https://doi.org/10.1093/cid/ciy008.

19. Wanga I, Helova A, Abuogi LL, Bukusi EA, Nalwa W, Akama E, et al. Acceptability of community-based mentor mothers to support HIVpositive pregnant women on antiretroviral treatment in western Kenya: a qualitative study. BMC Pregnancy Childbirth. 2019;19(1):288.

20. UNAIDS. Action, innovation and solidarity: Building on momentum to close the gaps and leave no one behind in western and central Africa 2018 [Available from: https://www.unaids.org/en/resources/docum ents/2018/20180725_WCA_momentum. Accessed 1 July 2021.

21. Sam-Agudu NA, Cornelius LJ, Okundaye JN, Adeyemi OA, Isah HO, Wiwa OM, et al. The Impact of Mentor Mother Programs on PMTCT Service Uptake and Retention-in-Care at Primary Health Care Facilities in Nigeria: A Prospective Cohort Study (MoMent Nigeria). J Acquir Immune Defic Syndr 1999. 2014;67(Suppl 2):S132-8.

22. Sam-Agudu NA, Ramadhani HO, Isah C, Erekaha S, Fan-Osuala C, Anaba $U$, et al. The Impact of Structured Mentor Mother Programs on Presentation for Early Infant Diagnosis Testing in Rural North-Central Nigeria: A Prospective Paired Cohort Study. J Acquir Immune Defic Syndr 1999. 2017;75(Suppl 2):S182-9.

23. Sam-Agudu NA, Ramadhani HO, Isah C, Anaba U, Erekaha S, Fan-Osuala C, et al. The Impact of Structured Mentor Mother Programs on 6-Month Postpartum Retention and Viral Suppression among HIV-Positive Women in Rural Nigeria: A Prospective Paired Cohort Study. J Acquir Immune Defic Syndr 1999. 2017;75(Suppl 2):S173-81.

24. National AIDS/STI Control Programme, Federal Ministry of Health Nigeria. Technical Report 2014: National HIV Seroprevalence Sentinel Survey Among Pregnant Women Attending Antenatal Clinics in Nigeria. 2015. Published by Dept. of Public Health, Federal Ministry of Health, Abuja, Nigeria.

25. Charmaz K. Constructing Grounded Theory: A Practical Guide Through Qualitative Analysis. 1st ed. London: Sage Publications; 2006.

26. Glaser B, Strauss A. The discovery of grounded theory: Strategies for qualitative research. New York: Taylor and Francis Group; 2017. https:// doi.org/10.4324/9780203793206.

27. Braun V, Clarke V. Using thematic analysis in psychology. Qual Res Psychol. 2006;3(2):77-101.

28. Neale J. Iterative categorization (IC): a systematic technique for analysing qualitative data. Addiction. 2016;111(6):1096-106.

29. Guest $G$, Bunce A, Johnson L. How many interviews are enough?: An experiment with data saturation and variability. Field Methods. 2006;18:59-62.

30. Tong A, Sainsbury P, Craig J. Consolidated criteria for reporting qualitative research (COREQ): a 32-item checklist for interviews and focus groups. Int J Qual Health Care. 2007;19(6):349-57. https://doi.org/10.1093/intqhc/ mzm042.

31. Akinde Y, Groves AK, Nkwihoreze H, Aaron E, Alleyne G, Wright C, et al. Assessing the Acceptability of a Peer Mentor Mother Intervention to Improve Retention in Care of Postpartum Women Living with HIV. Health Equity. 2019;3(1):336-42.

32. McLeish J, Redshaw M. 'We have beaten HIV a bit': a qualitative study of experiences of peer support during pregnancy with an HIV Mentor Mother project in England. BMJ Open. 2016;6(6):e011499. https://doi.org/ 10.1136/bmjopen-2016-011499.

33. Carbone NB, Njala J, Jackson DJ, Eliya MT, Chilangwa C, Tseka J, et al. "I would love if there was a young woman to encourage us, to ease our anxiety which we would have if we were alone": Adapting the Mothers2Mothers Mentor Mother Model for adolescent mothers living with HIV in Malawi. PLoS One. 2019;14(6):e0217693. https://doi.org/10.1371/journ al.pone.0217693.

34. Shroufi A, Mafara E, Saint-Sauveur JF, Taziwa F, Vinoles MC. Mother to Mother (M2M) peer support for women in Prevention of Mother to Child Transmission (PMTCT) programmes: a qualitative study. PLoS One. 2013;8(6):e64717. https://doi.org/10.1371/journal.pone.0064717.

35. Igumbor JO, Ouma J, Otwombe K, Musenge E, Anyanwu FC, Basera T, et al. Effect of a Mentor Mother Programme on retention of mother-baby pairs in HIV care: A secondary analysis of programme data in Uganda. PloS one. 2019;14(10):e0223332-e. https://doi.org/10.1371/journal.pone. 0223332

36. DiCarlo A, Fayorsey R, Syengo M, Chege D, Sirengo M, Reidy W, et al. Lay health worker experiences administering a multi-level combination intervention to improve PMTCT retention. BMC Health Serv Res. 2018;18(1):17.

37. Schmitz K, Basera TJ, Egbujie B, Mistri P, Naidoo N, Mapanga W, et al. Impact of lay health worker programmes on the health outcomes of mother-child pairs of HIV exposed children in Africa: A scoping review. PLoS One. 2019;14(1):e0211439. https://doi.org/10.1371/journal.pone. 0211439 .

38. Futterman D, Shea J, Besser M, Stafford S, Desmond K, Comulada W, et al. Mamekhaya: a pilot study combining a cognitive-behavioral intervention and mentor mothers with PMTCT services in South Africa. AIDS Care. 2010;22(9):1093-100

39. DiCarlo AL, Gachuhi AB, Mthethwa-Hleta S, Shongwe S, Hlophe T, Peters $\mathrm{ZJ}$, et al. Healthcare worker experiences with Option B+ for prevention 
of mother-to-child HIV transmission in eSwatini: findings from a two-year follow-up study. BMC Health Serv Res. 2019;19(1):210.

40. Erekaha SC, Cornelius LJ, Bessaha ML, Ibrahim A, Adeyemo GD, Fadare $M$, et al. Exploring the acceptability of Option B plus among HIV-positive Nigerian women engaged and not engaged in the prevention of mother-to-child transmission of HIV cascade: a qualitative study. Sahara J. 2018:15(1):128-37.

41. Sam-Agudu NA, Odiachi A, Bathnna MJ, Ekwueme CN, Nwanne G, Iwu EN, et al. "They do not see us as one of them": a qualitative exploration of mentor mothers' working relationships with healthcare workers in rural North-Central Nigeria. Hum Resour Health. 2018;16(1):47. https://doi.org/ 10.1186/s12960-018-0313-9.

42. Thomson KA, Telfer B, Opondo Awiti P, Munge J, Ngunga M, Reid A. Navigating the risks of prevention of mother to child transmission (PMTCT) of HIV services in Kibera, Kenya: Barriers to engaging and remaining in care. PloS one. 2018;13(1):e0191463-e. https://doi.org/10.1371/journal.pone. 0191463.

43. Odiachi A, Sam-Agudu NA, Erekaha S, Isah C, Ramadhani HO, Swomen $\mathrm{HE}$, et al. A mixed-methods assessment of disclosure of HIV status among expert mothers living with HIV in rural Nigeria. PloS one. 2020;15(4):e0232423. https://doi.org/10.1371/journal.pone.0232423.

44. Kane S, Kok M, Ormel H, Otiso L, Sidat M, Namakhoma I, et al. Limits and opportunities to community health worker empowerment: A multicountry comparative study. Soc Sci Med. 2016:164:27-34.

45. Jigssa HA, Desta BF, Tilahun HA, McCutcheon J, Berman P. Factors contributing to motivation of volunteer community health workers in Ethiopia: the case of four woredas (districts) in Oromia and Tigray regions. Hum Resour Health. 2018;16(1):57.

46. Glenton C, Colvin CJ, Carlsen B, Swartz A, Lewin S, Noyes J, et al. Barriers and facilitators to the implementation of lay health worker programmes to improve access to maternal and child health: qualitative evidence synthesis. Cochrane Database Syst Rev. 2013;2013(10):Cd010414. https:// doi.org/10.1002/14651858.CD010414.pub2.

47. Cataldo F, Kielmann K, Kielmann T, Mburu G, Musheke M. "Deep down in their heart, they wish they could be given some incentives": a qualitative study on the changing roles and relations of care among home-based caregivers in Zambia. BMC Health Serv Res. 2015;15:36

48. Topp SM, Carbone NB, Tseka J, Kamtsendero L, Banda G, Herce ME. "Most of what they do, we cannot do!" How lay health workers respond to barriers to uptake and retention in HIV care among pregnant and breastfeeding mothers in Malawi. BMJ Glob Health. 2020;5(6). https://doi.org/10. 1136/bmjgh-2019-002220.

49. UNAIDS. End Inequalities. End AIDS. Global AIDS Strategy 2021-2026. 2021 [Available from: https://www.unaids.org/en/resources/documents/ 2021/2021-2026-global-AIDS-strategy. Accessed 1 July 2021.

\section{Publisher's Note}

Springer Nature remains neutral with regard to jurisdictional claims in published maps and institutional affiliations.
Ready to submit your research? Choose BMC and benefit from:

- fast, convenient online submission

- thorough peer review by experienced researchers in your field

- rapid publication on acceptance

- support for research data, including large and complex data types

- gold Open Access which fosters wider collaboration and increased citations

- maximum visibility for your research: over 100M website views per year

At BMC, research is always in progress.

Learn more biomedcentral.com/submissions 